\title{
Go to Bed and You MIGHT Feel Better in the Morning-the Effect of Sleep on Affective Tone and Intrusiveness of Emotional Memories
}

\author{
Per Davidson $^{1,2,3}$ (D) E Edward Pace-Schott ${ }^{2,3,4}$ \\ Accepted: 28 December 2020 / Published online: 25 March 2021 \\ (C) The Author(s) 2021, corrected publication 2021
}

\begin{abstract}
Purpose of Review It is important to examine what effect sleep has after an emotional experience. More knowledge about this topic could help inform us whether there are any potential sleep interventions that could help make sure that memories of negative emotional experiences are processed in the most adaptive manner possible.

Recent Findings Findings on the role of sleep in altering reactivity to emotional stimuli have been highly varied, with significant findings in opposite directions. A new exciting development in the field is several studies finding that sleep seems to make memories of negative experiences less intrusive.

Summary This review has mainly aimed to give an overview of the field, and of which issues need to be resolved. We argue for there being a strong need for standardization of how data are analyzed and presented, as well as for better methods for determining to what extent the effects of sleep are specific for a particular memory, or represent general changes in emotional reactivity.
\end{abstract}

Keywords Sleep $\cdot$ Emotional memory $\cdot$ Emotional responses $\cdot$ Affect $\cdot$ Intrusions $\cdot$ PTSD

\section{Introduction}

There is a bi-directional link between sleep and affect $[1,2]$. When we feel stressed or anxious, our sleep will be worse, and a night of poor sleep will increase our stress and anxiety during the following day (for reviews, see [1, 2]). Beyond this change in general affect, sleep has also often been suggested to process particular emotional experiences. After a negative experience, there is a large chance that you have at some point been encouraged to "Go to bed, and you will feel better in the

This article is part of the Topical Collection on Sleep and Learning

Per Davidson

per.davidson@psy.lu.se

1 Department of Psychology, Lund University, Box 213, 221 00 Lund, Sweden

2 Department of Psychiatry, Massachusetts General Hospital, Boston, MA, USA

3 Department of Psychiatry, Harvard Medical School, Boston, MA, USA

4 Athinoula A. Martinos Center for Biomedical Imaging, Charlestown, MA, USA morning" - an old adage that reflects a popular belief that such experiences are somehow processed during sleep in a way that makes us feel less bad about them. In this review, we have examined the scientific literature on the role of sleep in the processing of emotional memories, to investigate to what extent the claim made in that adage can actually be empirically supported.

We have focused on work regarding two different research questions. The first is on how sleep affects the emotional tone associated with a certain memory. As we do not yet know enough about the role of sleep in the processing of emotional experiences to start conducting experiments on people who have suffered actual negative emotional experiences (such as people coming into the ER after a traumatic event), the work on this topic is still being conducted through lab models of such experiences. Typically, this means exposing participants to images or video clips with negative emotional content while recording their emotional reactivity through subjective ratings and/or various kinds of physiological measurements. Then, after a delay interval containing either sleep or wake, participants are re-exposed to the same stimuli, and their emotional responses are again measured. This allows us to measure how sleep and wake differentially affect changes in emotional responses, and if different factors during sleep, such as time 
spent in specific sleep stages, contribute differently to any potential sleep-dependent changes. To be able to say if sleep affects emotional memories, one must also include novel stimuli during the re-test. This is necessary in order to determine what changes in reactivity can be attributed to sleepdependent processing of emotional stimuli seen before the delay interval, and to what degree changes in responses just represent a general sleep-dependent change in emotional reactivity, not particular to any specific memories.

In the second part of the paper, we review a recent and very exciting development in the field, which are studies on whether sleep affects the degree to which participants involuntary come to think about an emotional experience. Throughout the review, we will also discuss methodological issues that can sometimes make it difficult to know what to make of the experimental findings in the field to date. More knowledge about the role of sleep in the processing of emotional memories is very important as it could be of great clinical relevance to know whether sleep should be promoted or not immediately after a negative experience, and if sleep can somehow be manipulated to ensure that the memory of such an experience is processed in the most adaptive manner.

To limit the scope, we have only focused on studies that have used intrinsically emotional stimulus material, and that have used emotional reactions or intrusions as the outcome measures. We have not included findings concerning the consolidation of declarative memories or studies using fear conditioning paradigms. The latter field of study has revealed contrasting results regarding the role of sleep in the consolidation of fear learning. Sleep, and especially rapid eye movement (REM) sleep, has, however, been repeatedly found to be involved in the consolidation of fear extinction, even though the exact nature of these effects has been highly varied between studies [3]. Studies on targeted-memory reactivation have also been outside the scope of this review (for a review on this topic, see [4]).

\section{How Sleep Affects Emotional Reactivity}

One influential theory suggests that during sleep, and especially during REM sleep, emotional experiences are reactivated in a state devoid of the adrenergic tone that they have come to be associated with during wake [5]. This would then allow for the processing of these experiences in a state with less physiological arousal, resulting in a reduction of their associated affective tone. Other accounts, however, suggest that sleep, and especially REM sleep, given its high rate of activity in regions of the brain associated with emotional processing, might instead reinforce the emotional salience of a memory [6-8]. As will be evident in this review paper, however, the literature has yielded so many contrasting findings that no theoretical account can be said to have broad empirical support at this point.

We have divided the presentation of results based on the outcomes measurement used. When several outcome measurements have been used in the same study, we have divided the study such that the results of the different outcome measurements are mentioned in their respective sections. We have only mentioned findings where there has been a significant interaction (or trends toward an interaction) between session (before/after the delay interval) and group (sleep/wake), or when there has been a significant group difference in between-sessions change scores. Thus, we have not reported results when there has been an effect in one group, but not in the other, without there being a significant group difference in change scores. This has been in an effort to make results more comparable between studies, as some studies have not even made post hoc tests when such tests have not been warranted by significant interactions. When the sleep and wake groups have been tested at different times of the day, it is important to keep in mind that group differences can be caused by circadian differences in subjective or physiological reactivity. Hot et al. [9] for example found lower responses to emotional stimuli in the morning and early afternoon, which then increased and peaked at $3.30 \mathrm{pm}$ and decreased again in the evening, but not to as low a level as in the morning. Regarding mood (i.e. enduring affective states not necessarily triggered by specific stimuli), it has been found that positive affect in healthy subjects is low in the morning, then increases during the day, to then decrease again during the evening $[10,11]$. Negative affect, on the other hand, seems to show much less diurnal variation $[10,11]$. Some studies have controlled for circadian rhythms in different ways (e.g., by including additional control groups), whereas others have not. This is, however, beyond the scope of this review, and will not be discussed further, but we urge the reader to keep this in mind.

\section{Subjective Ratings}

Most studies have asked participants to rate stimuli for valence and arousal, respectively, whereas some have only asked participants to rate them less specifically for degree of "emotional intensity". We will first present studies comparing the effect of sleep and wake, and then studies examining the different contributions of specific factors during sleep. In the few cases where it has not been possible to disentangle the effect of sleep in general from the effect from different sleep stages, we have presented those studies in the section where we have found them the most suitable. Studies comparing how sleep and wake differentially affect changes in subjective ratings of emotional stimuli are presented in Table 1.

As evident in Table 1, there has been a huge variation of findings. Sleep, compared to wake, has been found to both increase and decrease emotional reactivity. Even among those 


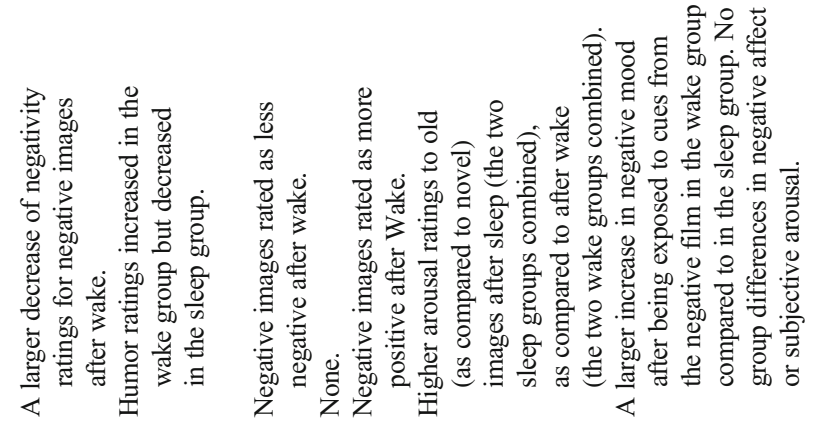

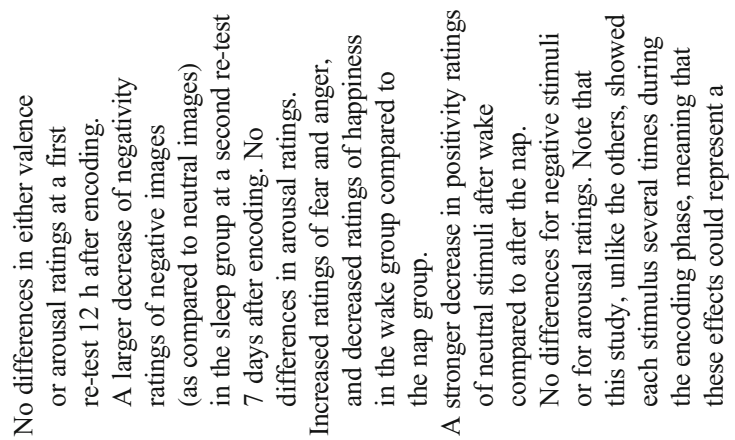<smiles>[Y]C1(C)[C@@H](C)[C@@H]1C</smiles>

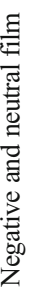

㱛

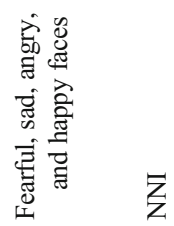

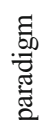

$\sum_{3}^{n} \sum_{0}^{n}$

.

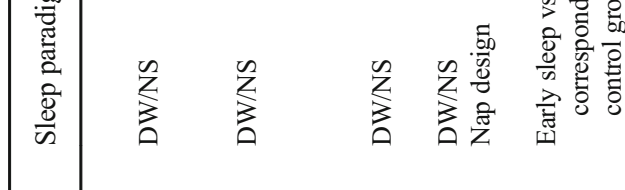

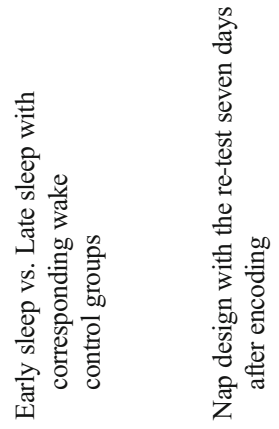

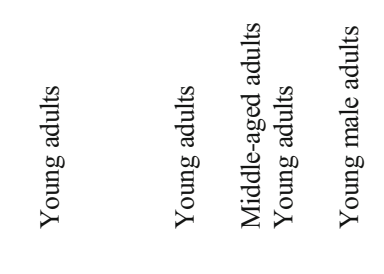

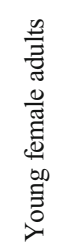

$\sum_{z}^{n}$

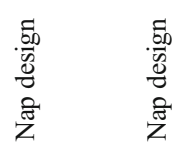

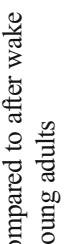

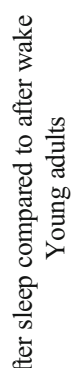

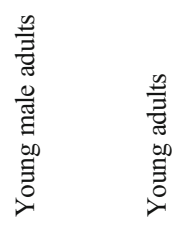

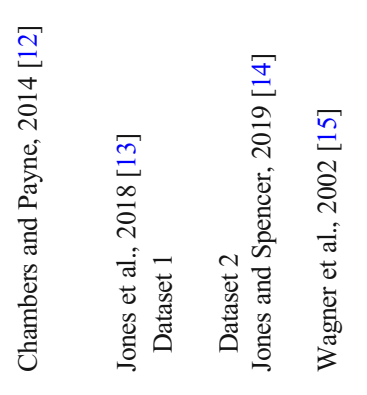
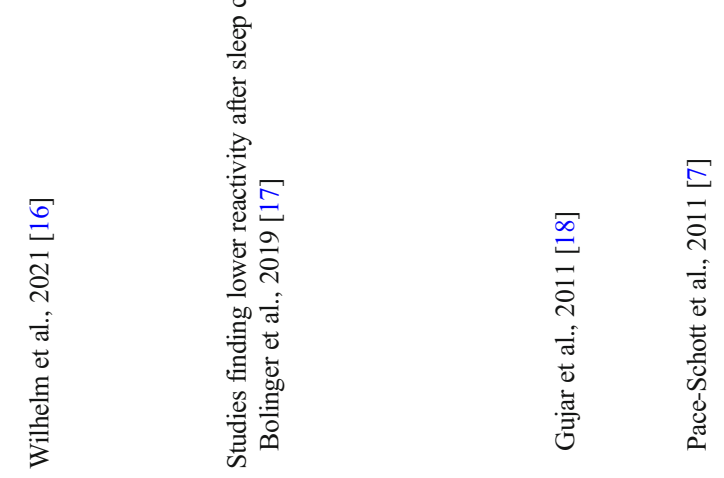


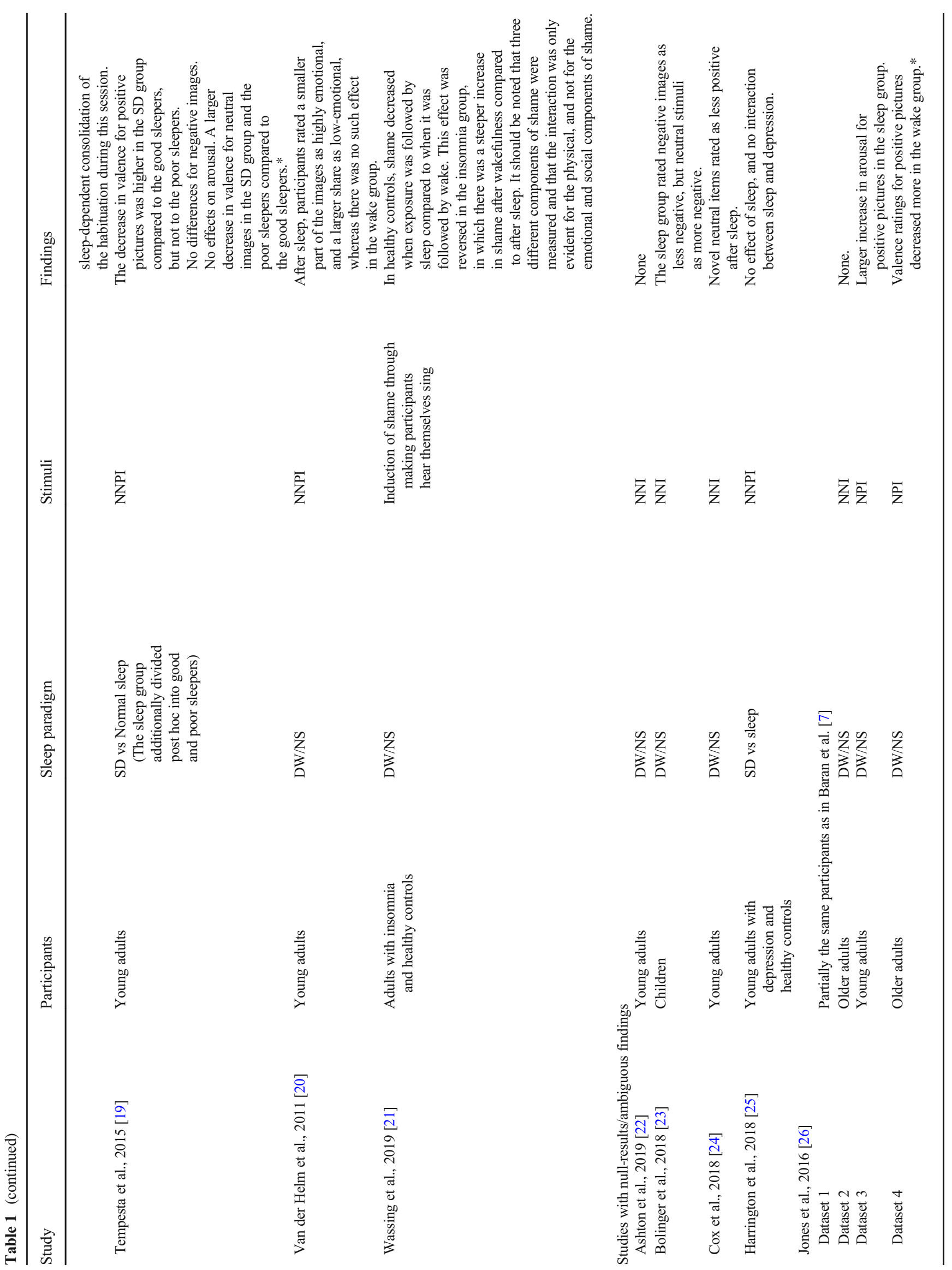


studies finding effects in the same direction, the exact nature of the findings has still been highly varied. Some have found effects on valence, some on arousal, some for the emotional stimuli, and some for the neutral stimuli. Some studies have found sleep to mainly affect the previously seen stimuli, whereas others have found sleep to mainly affect ratings of the novel stimuli.

One reason why sleep/wake contrasts have revealed such contrasting findings could be that sleep consists of many different factors that cannot be lumped together. It is for example possible that different sleep stages affect emotional reactivity in different directions. It has further been suggested that good sleep decreases emotional reactivity, whereas restless and disturbed sleep does not. Poor sleep quality and restless sleep have also been suggested as factors that perpetuate affective disorders via an impaired ability to process the memory for emotional experiences in an adaptive manner. In Table 2, we have listed studies that have sought to correlate different features of sleep (such as time spent in different sleep stages) with changes in emotional reactivity, as well as studies that have compared different kinds of sleep with each other. The latter includes comparisons of sleep during the early half of the night (which contains little REM sleep) with sleep in the later (REM-rich) half of the night, and studies that have subjected participants to sleep manipulations such as selective REM deprivation (REMD). We have only reported significant findings, and we have not included correlations that only involved a certain portion of the night, such as the percentage of REM sleep during the fourth quarter of the night. When a table entry says "no correlations," it means there were no significant correlations, and when it says "none reported," it means information about correlations has not been reported in the paper.

As evident in Table 2, no sleep stage has consistently been replicated to be associated with sleep-dependent changes in emotional reactivity. Furthermore, the stage most hypothesized to be involved in changing the affective tone associated with emotional memories, REM sleep, has been found to result in significant effects in contrasting directions.

\section{Studies Using Physiological and Neural Measurements}

\section{Skin Conductance Responses}

For skin conductance responses (SCRs), two studies have shown sleep to decrease emotional reactivity compared to wake [7, 41], and two have found no group differences [22, 42]. One of the studies reporting a null-result [42] combined participants suffering from post-traumatic stress disorder (PTSD), trauma-exposed controls, and healthy controls to examine whether the different sleep patterns in these groups would have different effects on changes in emotional reactivity, which was not the case. Other studies have reported higher 
SCRs after sleep as compared to after wake [14, 27, 43]. Regarding the active mechanisms during sleep, Pace-Schott et al. found reduced reactivity only in those participants who did not enter REM sleep during their nap, and not in those who did [7]. All other polysomnographic studies have either not found any correlations, or not reported data on this $[8,14$, $41,42]$. One study found higher skin conductance levels to a sad story after a long nap as compared to after a short one [31], but no correlations with any sleep variables. An early study did not find any effect of REMD on changes in reactivity to a negative film [32].

\section{Heart Rate Deceleration}

Studies using heart rate deceleration (HRD) as the outcome measurement have yielded similarly contrasting results. In some studies, sleep has been found to decrease responses to emotional stimuli compared to wake [14, 41], whereas other studies have found sleep to increase responses [7, 22, 23]. One study [17] found higher responses in the sleep group at a retest immediately after the delay interval, but lower responses at a second re-test taking place one week later. One study found no group differences [16], and another study found no effect of pharmacological norepinephrine reduction during sleep on subsequent heart rate responses to emotional stimuli [33]. One study combining participants suffering from PTSD with both trauma-exposed and non-trauma-exposed controls found sleep to decrease responses in several different heart rate-related measures [42]. No study has reported any correlations between any sleep variable and changes in $\operatorname{HRD}[7,14$, $16,17,22,23,33,41,42]$.

\section{Corrugator Electromyography}

Some studies have measured emotional reactivity by applying electrodes to the corrugator supercilii muscle, which is located at the medial end of the eyebrow, and is also known as the "frowning" muscle. One study found increased corrugator electromyography (cEMG) responses [14] after a nap as compared to after wakefulness, whereas another study found an effect in the opposite direction [7]. In the latter study, this sleep-dependent decrease was only evident for those who entered slow-wave sleep during their nap. No study has reported any correlations between any sleep variable and changes in cEMG $[7,8,14]$.

\section{Event-Related Potentials}

Three studies have measured sleep-dependent changes in emotional reactivity through event-related potentials (ERPs) using electroencephalography (EEG). One study found larger late positive potentials (LPPs), a component that increases as a function of the emotional intensity of the stimuli being viewed [44], in the wake group as compared to the sleep group [23].
Similar results were found in another study at an immediate re-test, but no group differences were present at a second retest one week later [17]. Neither of these studies found any correlations between ERP magnitudes and any sleep variables. Another study found that LPPs to emotional pictures correctly classified as "previously seen" were larger after late sleep than after early sleep [34].

\section{Functional Magnetic Resonance Imaging}

Here we have mainly focused on results regarding the amygdala. The only study to contrast a sleep and a wake group without also assessing memory performance [20] found a larger decrease of amygdala responses after sleep. The other studies have mainly been interested in neural changes related to sleep-dependent memory consolidation, and they have analyzed this in different ways, making the results difficult to compare. Two such studies have found increased activity in the amygdala for correctly remembered negative items after sleep $[45,46]$. One study found higher activity in the amygdala after sleep deprivation compared to after sleep when viewing negative pictures at an immediate memory test [47], but the opposite effect after a second test 6 months later, with higher amygdala activity in the sleep group [48].

Regarding which factors during sleep that are associated with changes in emotional reactivity, one study found that the decrease in amygdala activity during sleep was correlated with frontal gamma activity (a putative marker of adrenergic tone), such that those with less frontal gamma activity during sleep had a larger decrease of amygdala responses [20]. Another study [38] found a decrease of activity in several brain regions related to emotional processing (but not in the amygdala) after a night with interruptions of non-REM sleep, whereas activity remained the same or increased after a night of selective REMD. It has also been found that pharmacologically increasing cortisol during sleep decreased amygdala activity during the retest [49]. Another study found that the decrease in amygdala activity was correlated with the duration of REM sleep, but only when the REM went on for long continuous periods, and not in those participants whose REM sleep was frequently interrupted [50].

\section{Summary}

Findings on the role of sleep in changing emotional reactivity have been highly varied both for subjective ratings and for physiological and neural measurements. Thus, at the moment, we really have very little idea how sleep and wake differentially affect emotional reactivity. One reason why similar studies generate such different outcomes could be that many of the effects are random effects from underpowered studies [51]. 


\begin{tabular}{|c|c|c|c|c|c|c|}
\hline Z元充 & z & Z 玄 & 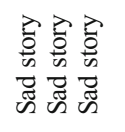 & $\begin{array}{l}\stackrel{\mathscr{E}}{\overbrace{0}} \\
\check{z}\end{array}$ & 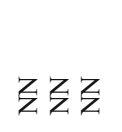 & 玄云 \\
\hline 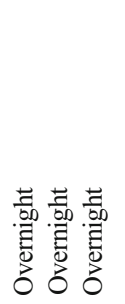 & 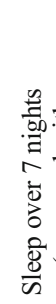 & 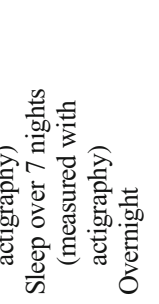 & 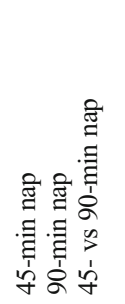 & 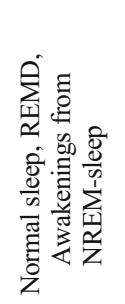 & 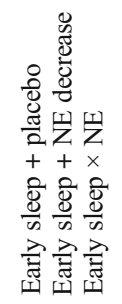 & 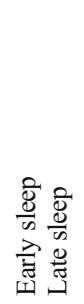 \\
\hline
\end{tabular}

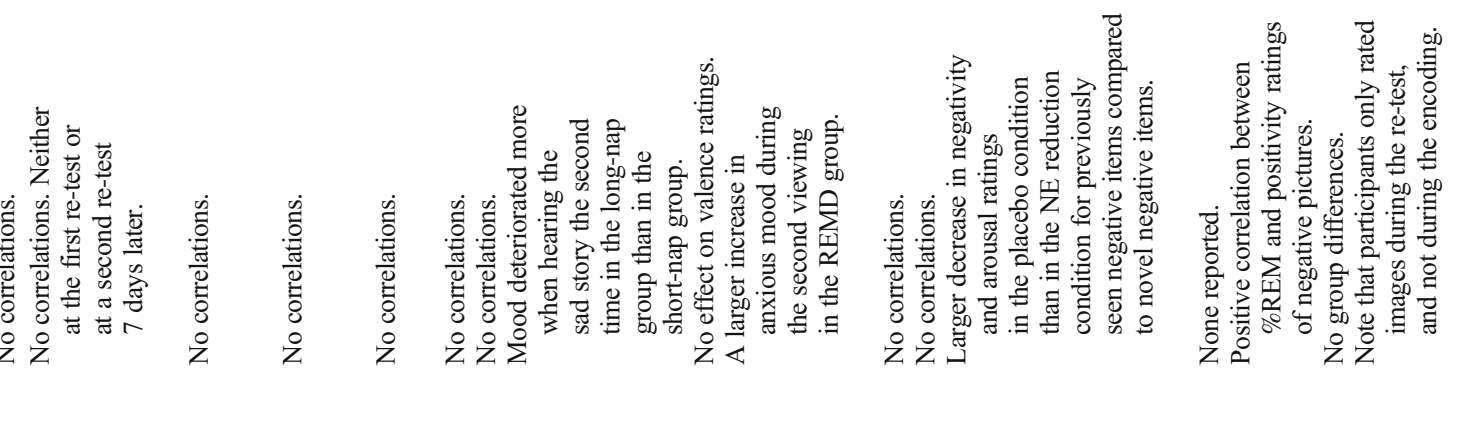
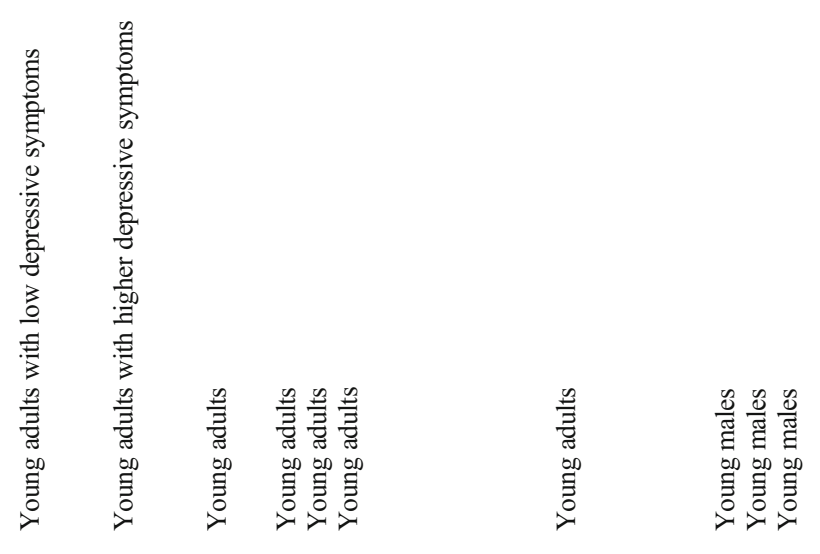

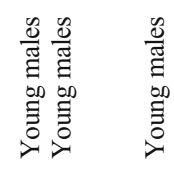

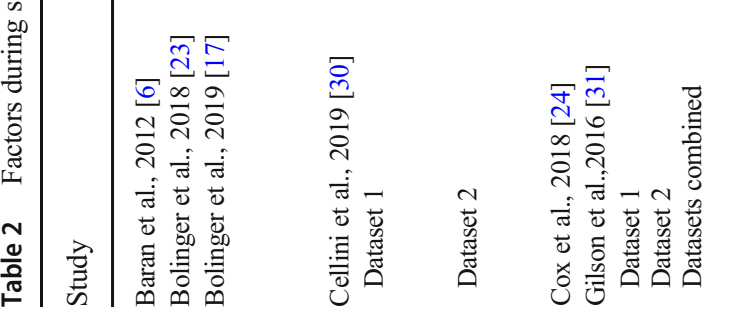

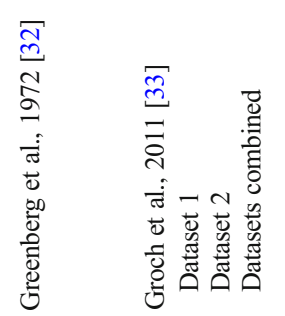

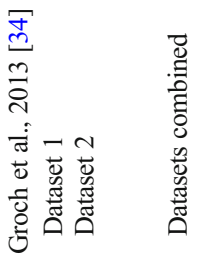




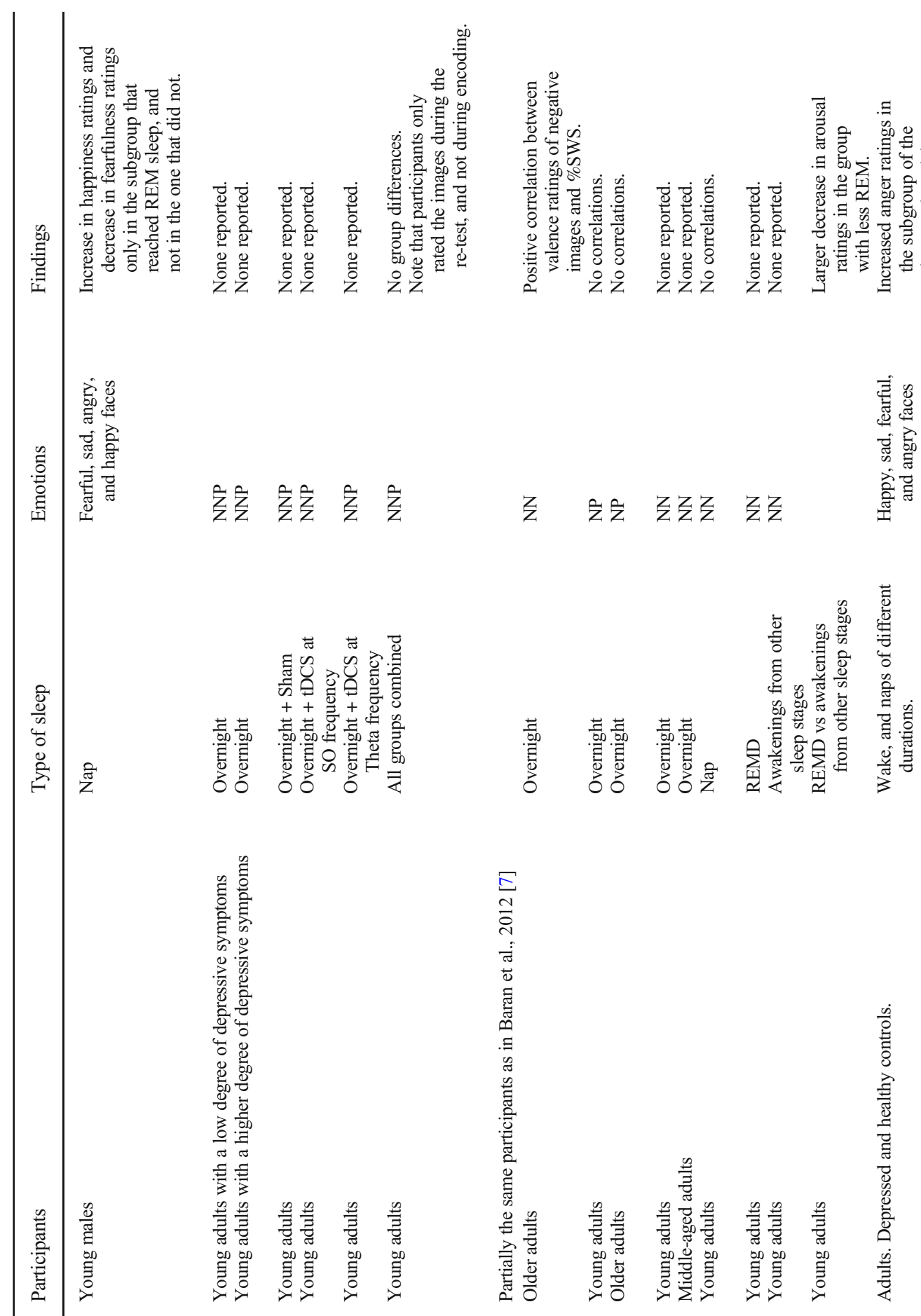

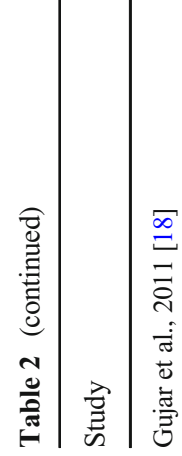
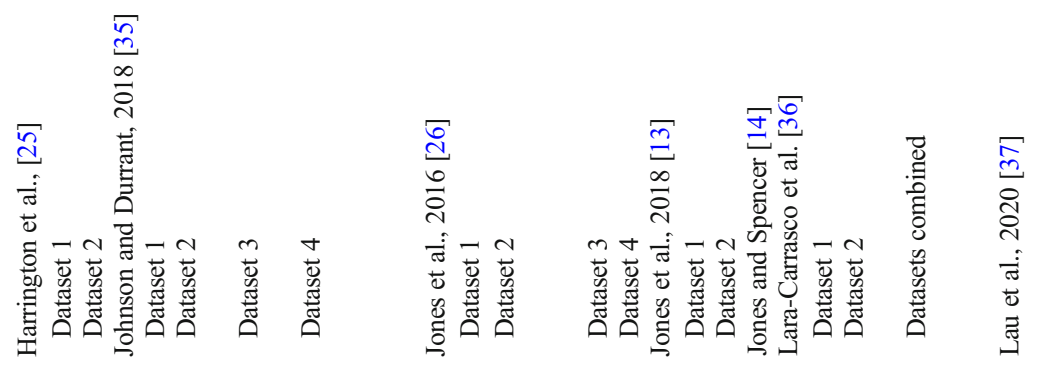


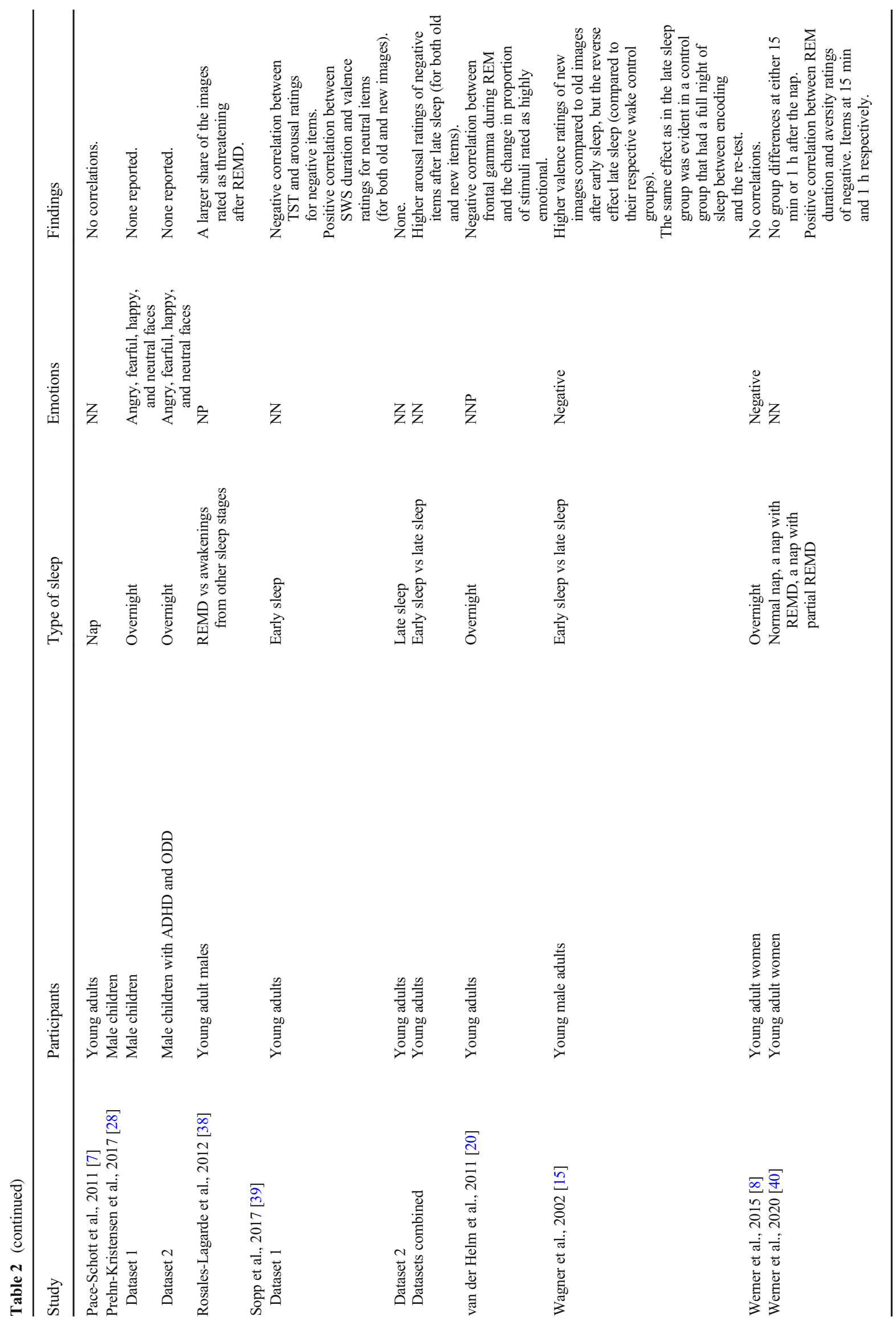




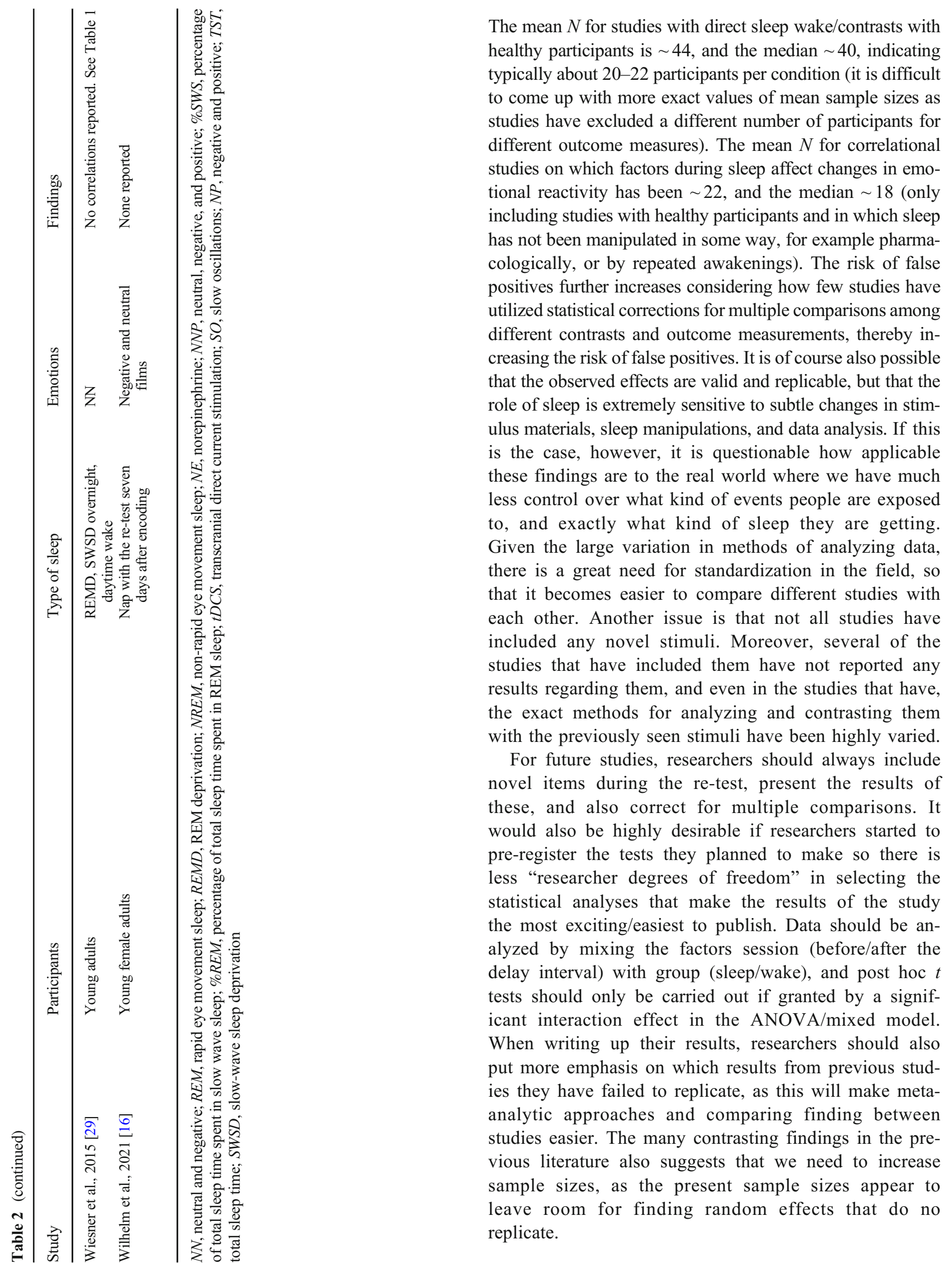




\section{Sleep Seems to Make Negative Memories Less Intrusive}

An exciting new development is studies that examine whether sleep in the immediate aftermath of viewing film clips with traumatic content makes the memory of such films more or less intrusive. Intrusions are a core feature of PTSD, and intrusive memories soon after trauma have been shown to predict the later development of this disorder [52], even if we at the moment do not know if this has a causal component or is just a predictor. This association makes it important to determine whether there are simple interventions that can be applied immediately after a traumatic experience in order to make the memory of it less intrusive.

In these analog trauma studies, participants have typically viewed video clips containing traumatic events (e.g., physical and sexual violence, motor vehicle accidents, self-harm), and then either slept or remained awake after encoding. Participants have then kept a diary for a period of time after watching the movie, typically a week, documenting how many intrusive memories of the movie they have experienced.

The first study using this paradigm found lower scores on the Impact of Event Scale [53] the following day in the group subjected to sleep deprivation during the night after watching the film, as well as fewer intrusions during the six days postencoding [54]. This effect was driven by fewer intrusions during the first two days in the sleep deprivation group.

Since this first study was published, most studies have pointed in the opposite direction. Kleim et al. found fewer intrusions, and lower affective tone associated with these intrusions, in the group that slept after viewing the analog trauma film [55]. Interestingly, these differences were more pronounced during the latter part of the study week. Using a similar design, Zeng et al. found fewer intrusions in the sleep group, but no group difference in distress associated with these intrusions [56]. They further found higher scores on the hyperarousal subscale of the Impact of Event Scale in the sleep-deprived group after one week, but not on the intrusions or avoidance subscales.

Woud et al. found fewer intrusions and fewer post-traumatic cognitions after sleep in a nap design [57••], and Sopp et al. found that normal sleep, compared to partial sleep deprivation, after viewing a traumatic picture story resulted in fewer intrusions during a task designed to trigger intrusions the next day [58]. This latter effect was however not replicated in a design comparing daytime wake with nighttime sleep [59]. One study found no differences in intrusions or in intrusion distress (after removing two outliers) between a sleep and a sleep deprivation group [60], and one study found no differences in the number of intrusions, intrusion distress, or on scores on the Impact of Event Scale between a nap and wake group [16].

Some studies on this topic have been correlational and observational rather than experimental. Luik et al. recruited participants coming into the emergency department after an actual traumatic experience and found a positive correlation between sleep difficulties and intrusive memories during the week following the traumatic event [61•]. Another study found a U-shaped association between sleep duration on the post-trauma night and the number of intrusions during the following week, such that the quantiles with the shortest ( $\sim 1 \mathrm{~h}$ of sleep) and longest $(\sim 12.5 \mathrm{~h})$ sleep durations respectively experienced the most intrusions $[62 \bullet \cdot$. Sleep duration during the first night post-trauma did, however, not predict subsequent PTSD at a one-month follow-up.

\section{Factors during sleep that make memories more or less intrusive}

Studies examining which factors during sleep predict intrusions have also found some interesting results, even though it, similarly to the studies on sleep and emotional reactivity, is problematic that no finding has been exactly replicated between studies. One study found that the amount of stage 2 sleep and the density of parietal sleep spindles correlated negatively with the number of intrusions, and that increased wake after sleep onset, REM density, and time spent in stage 1 sleep were positively correlated with the number of intrusions [55]. Another study found that higher theta activity during REM was associated with fewer intrusions, and that REM duration was negatively correlated with scores on the Impact of Event Scale [63*0] (neither of these latter two correlations were significant immediately after awakening, but rather on day 4). Similar results were found in another study where theta activity during REM was negatively correlated with the number of intrusions, and REM duration was negatively correlated with intrusion distress [16]. This study also found a negative correlation between slow-wave activity and intrusion distress. One study found the duration of slow-wave sleep to be negatively correlated with the numbers of intrusions in a task designed to trigger these during the next day [59]. An additional study found more intrusions in a group of participants with PTSD compared to trauma-exposed controls and a non-traumaexposed control group, and that this group effect was mediated by increased REM behavior disorder symptomology in the PTSD group [64].

One must be careful in drawing causal conclusions from variables that have not been experimentally manipulated (such as time spent in different sleep stages). This is because those who have the most impaired sleep after a traumatic experience may also be those who were the most negatively affected by the experience, making poor sleep a marker of event-impact rather than a causal mechanism. Porcheret et al. [62••], for example, found the same Ushaped relationship when looking at changes in sleep between the pre-trauma night (measured retrospectively) and the posttrauma night, during which large changes in sleep (in both directions) predicted more intrusions. Similarly, Sopp et al. [63・•] found that those who had the most negative reaction to the trauma film also showed the largest decrease in REM duration. In this study, compared to a control group that watched a neutral film, the trauma film watchers had increased wake after sleep onset, shorter 
stage 2 sleep, and longer slow-wave sleep duration, once again indicating that a certain sleep pattern can be a marker of a negative event rather than a causal mechanism for future symtoms. Wilhelm et al. [16] found that increased affective responses to the trauma film was associated with it taking taking a longer time to fall asleep, and in decreased REM duration.

There is also the issue of the third variable problem, whereby both sleep disturbances and an impaired ability to process an emotional experience could be associated, without there necessarily being a causal connection between them. Sleep is for example disturbed in several mood and anxiety disorders that are also related to difficulties in emotional processing, and in keeping unwanted thoughts, emotions, and memories out of awareness $[65,66,67 \bullet]$. One study found that general insomnia symptoms (measured prior to watching the traumatic film) predicted more PTSD symptoms (including intrusions) after watching it [68]. This suggests that a certain sleep pattern (such as more restless sleep, more fragmented REM sleep, or less slow-wave sleep) might be a general marker of proneness to developing such symptoms rather than a causal factor (even if it is of course possible that in this study, the effect was mainly mediated by disturbed sleep on the post-film night). To the best of our knowledge, the only study to selectively manipulate REM sleep in an intrusion paradigm found that REMD during a nap increased both the number of intrusions and their degree of aversiveness compared to naps containing more REM [40].

Another study found that sleep deprivation made it more difficult to suppress retrieval of images encoded during the previous evening when exposed to a reminder of them [69]. Other studies have examined the effect of sleep on emotional memories that have been subjected to some form of suppression before a delay interval containing either sleep or wake. The aim of this approach has been to examine if such suppression is consolidated by sleep, or on the contrary, if sleep is a state where previously suppressed memories are restored. Kuriyama et al. [43] had participants view video clips of motor vehicle accidents and asked them to either try to memorize what they were watching, or to attempt to immediately forget it. This was followed by either sleep deprivation or a night of normal sleep. Results revealed increased emotional responses after sleep deprivation as compared to after normal sleep in participants who had been asked to try to forget what they were watching during encoding. The opposite was, however, found in the group of participants who had received instructions to remember, with lower responses after sleep deprivation. The two studies that have examined if sleep makes emotional memories previously subjected to suppression (during encoding or retrieval respectively) either more or less accessible for voluntary retrieval have not found any such effects $[70,71]$.

One important task for future research will be to determine whether the changes in the number of intrusions are caused by the memory having been processed in a different way during sleep and wake, or by a general effect of sleep loss increasing susceptibility to all kinds of intrusive thoughts. Cox et al. [72] found that the association between the severity of combat exposure and re-experiencing symptoms became stronger with increased degrees of insomnia symptoms. Another study found that sleep disturbances in soldiers before deployment predicted the degree of re-experiencing symptoms post-deployment [73]. Studies recording day-to-day variations in sleep have found that participants with PTSD had increased intrusion symptomology after nights with shorter sleep duration [74], and that mindwandering in general increases after nights with poor sleep [75].

Contrary to a view in which the effects are driven primarily by general changes in cognitive control ability are studies finding the effect of intrusions still being present, and in some cases, stronger, after several days when the immediate effect of any sleep-related changes in cognitive functioning would be expected to have worn off $[55,63 \bullet \cdot]$. Such effects should instead indicate that sleep on the post-learning night affects the consolidation of the memory in some way. For more detailed reviews on sleep and intrusions, and for a discussion of non-experimental, observational studies on sleep after traumatic experiences, see [76, 77].

\section{Conclusions}

Sleep disturbances have been shown to be a predictor of future mental disorders [78, 79]. It has further been found that sleep disturbances before a negative life event predict increased risks of developing PTSD and depression after it, something that has been mostly studied by examining soldiers before and after deployment to a warzone [80-82, but see also 83]. In addition, a study in civilians found that sleep disturbances immediately prior to a traumatic experience predicted subsequent incident psychiatric disorders [84]. Future studies should examine the degree to which sleep disturbances play a causal role in the development of psychiatric disorders, and to what extent they are prodromal symptoms. A further possibility is that poor sleep is a general marker of increased vulnerability to being severely impacted by a negative event. Studies have, for example, found that childhood adversity predicts later sleep problems $[85,86]$. Clearly determining causality will be difficult as the degree of negative experiences and sleep manipulations necessary for experimental studies is limited for ethical and practical reasons. One promising way to determine whether there is a causal effect of sleep is by examining the prospective effect of sleep-improving interventions. Christensen et al. [87] for example found that treating insomnia decreased depressive symptoms in a prospective study with a large sample size.

In this review, we have examined the experimental work on sleep and emotional memory. More knowledge about this topic could help us find out to what degree the association between sleep disturbances and poor mental health can be explained by a role for sleep in decreasing the affective impact associated with emotional experiences. As we have seen, however, the results regarding sleep and emotional reactivity have been highly variable and sometimes contradictory. In contrast, studies on the role 
of sleep in decreasing intrusive thoughts related to the experience seem to show more consistent findings, even though there have been much fewer studies on this topic. A task for future studies will be to determine to what degree the effects can be explained by sleep simply changing emotional reactivity in general [1, 2], and to what degree this effect is mediated by sleep increasing cognitive control and emotional regulation ability in a general manner (for a discussion of this, see for example [88, 89, 90*, 91]), not specific to a particular memory. This question might seem to be of academic interest only. If sleep makes us feel better about a negative experience, it might appear less important exactly why. If the effect of sleep comes from it consolidating the memory on the post-encoding night, this would, however, mean that it is critical to rapidly target sleep immediately during the night after the emotional experience.

For future research, it is important to remember that sleep can be a lot of different things, and it is possible that the good sleep we have on the night after a normal day has positive effects for our emotional well-being, whereas the restless sleep we would have after a negative emotional experience might not. This is important to keep in mind so that we are not comparing apples to oranges when asking what the role of sleep is. To return to the adage mentioned in the introduction, we would like to say that even if we do not know what effect sleep might have in altering the emotional tone associated with an emotional experience, sleep serves many other important functions, such as a general improvement of mood [92]. Therefore, until there is clear evidence saying that sleep after an emotional experience has negative consequences, we would still say that going to bed is generally a good idea, and that it will increase your chances of feeling better in the morning.

Acknowledgments We gratefully acknowledge Jovi Ige for help with proof reading.

Funding Open Access funding provided by Lund University. Per Davidson is supported by a grant from the Swedish Research Council (Grant\# 2017-06383). Edward Pace-Schott is supported by NIH/NIMH R21MH121832.

\section{Compliance with Ethical Standards}

Conflict of Interest Neither author has any conflicts of interests to declare.

Human and Animal Rights and Informed Consent This article does not contain any studies with human or animal subjects performed by any of the authors.

Open Access This article is licensed under a Creative Commons Attribution 4.0 International License, which permits use, sharing, adaptation, distribution and reproduction in any medium or format, as long as you give appropriate credit to the original author(s) and the source, provide a link to the Creative Commons licence, and indicate if changes were made. The images or other third party material in this article are included in the article's Creative Commons licence, unless indicated otherwise in a credit line to the material. If material is not included in the article's
Creative Commons licence and your intended use is not permitted by statutory regulation or exceeds the permitted use, you will need to obtain permission directly from the copyright holder. To view a copy of this licence, visit http://creativecommons.org/licenses/by/4.0/.

\section{References}

Papers of particular interest, published recently, have been highlighted as:

- Of importance

•• Of major importance

1. Kahn M, Sheppes G, Sadeh A. Sleep and emotions: bidirectional links and underlying mechanisms. Int J Psychophysiol. 2013;89(2): 218-28. https://doi.org/10.1016/j.ijpsycho.2013.05.010.

2. Tempesta D, Socci V, De Gennaro L, Ferrara M. Sleep and emotional processing. Sleep Med Rev. 2018;40:183-95. https://doi.org/ 10.1016/j.smrv.2017.12.005.

3. Davidson P, Pace-Schott E. The role of sleep in fear learning and memory. Curr Opin Psychol. 2020;34:32-6. https://doi.org/10. 1016/j.copsyc.2019.08.016.

4. Hu X, Cheng LY, Chiu MH, Paller KA. Promoting memory consolidation during sleep: a meta-analysis of targeted memory reactivation. Psychol Bull. 2020;146(3):218-44. https://doi.org/10.1037/ bul0000223.

5. Walker MP, van der Helm E. Overnight therapy? The role of sleep in emotional brain processing. Psychol Bull. 2009;135(5):731-48. https://doi.org/10.1037/a0016570.

6. Baran B, Pace-Schott EF, Ericson C, Spencer RMC. Processing of emotional reactivity and emotional memory over sleep. J Neurosci. 2012;32(3):1035-42. https://doi.org/10.1523/jneurosci.2532-11. 2012.

7. Pace-Schott EF, Shepherd E, Spencer RMC, Marcello M, Tucker M, Propper RE, et al. Napping promotes inter-session habituation to emotional stimuli. Neurobiol Learn Mem. 2011;95(1):24-36. https://doi.org/10.1016/j.nlm.2010.10.006.

8. Werner GG, Schabus M, Blechert J, Kolodyazhniy V, Wilhelm FH. Pre- to postsleep change in psychophysiological reactivity to emotional films: late-night REM sleep is associated with attenuated emotional processing. Psychophysiology. 2015;52(6):813-25. https://doi.org/10.1111/psyp.12404.

9. Hot P, Leconte P, Sequeira H. Diurnal autonomic variations and emotional reactivity. Biol Psychol. 2005;69(3):261-70. https://doi. org/10.1016/j.biopsycho.2004.08.005.

10. Clark LA, Watson D, Leeka J. Diurnal variation in the positive affects. Motiv Emot. 1989;13(3):205-34. https://doi.org/10.1007/ BF00995536.

11. Peeters F, Berkhof J, Delespaul P, Rottenberg J, Nicolson NA. Diurnal mood variation in major depressive disorder. Emotion. 2006;6(3):383-91. https://doi.org/10.1037/1528-3542.6.3.383.

12. Chambers AM, Payne JD. Laugh yourself to sleep: memory consolidation for humorous information. Exp Brain Res. 2014;232(5): 1415-27. https://doi.org/10.1007/s00221-013-3779-7.

13. Jones BJ, Mackay A, Mantua J, Schultz KS, Spencer RMC. The role of sleep in emotional memory processing in middle age. Neurobiol Learn Mem. 2018;155:208-15. https://doi.org/10.1016/ j.nlm.2018.08.002.

14. Jones BJ, Spencer RMC. Sleep preserves subjective and sympathetic emotional response of memories. Neurobiol Learn Mem. 2019;166:107096. https://doi.org/10.1016/j.nlm.2019.107096. 
15. Wagner U, Fischer S, Born J. Changes in emotional responses to aversive pictures across periods rich in slow-wave sleep versus rapid eye movement sleep. Psychosom Med. 2002;64(4):627-34. https://doi.org/10.1097/01.psy.0000021940.35402.51.

16. Wilhelm I, Azza Y, Brennwald K, et al. Investigating the effect of a nap following experimental trauma on analogue PTSD symptoms. Scientific Reports. 2021;11(1):4710. https://doi.org/10.1038/ s41598-021-83838-1.

17. Bolinger E, Cunningham TJ, Payne JD, Bowman MA, Bulca E, Born J, et al. Sleep's benefits to emotional processing emerge in the long term. Cortex. 2019;120:457-70. https://doi.org/10.1016/j. cortex.2019.07.008.

18. Gujar N, McDonald SA, Nishida M, Walker MP. A role for REM sleep in recalibrating the sensitivity of the human brain to specific emotions. Cereb Cortex. 2011;21(1):115-23. https://doi.org/10. 1093/cercor/bhq064.

19. Tempesta D, De Gennaro L, Natale V, Ferrara M. Emotional memory processing is influenced by sleep quality. Sleep Med. 2015;16(7):862-70. https://doi.org/10.1016/j.sleep.2015.01.024.

20. van der Helm E, Yao J, Dutt S, Rao V, Saletin Jared M, Walker MP. REM sleep depotentiates amygdala activity to previous emotional experiences. Curr Biol. 2011;21(23):2029-32. https://doi.org/10. 1016/j.cub.2011.10.052.

21. Wassing R, Benjamins JS, Talamini LM, Schalkwijk F, Van Someren EJW. Overnight worsening of emotional distress indicates maladaptive sleep in insomnia. Sleep. 2019;42(4). doi:https://doi. org/10.1093/sleep/zsy268.

22. Ashton JE, Harrington MO, Guttesen AV, Smith AK, Cairney SA. Sleep preserves physiological arousal in emotional memory. Sci Rep. 2019;9(1):5966. https://doi.org/10.1038/s41598-019-42478-2.

23. Bolinger E, Born J, Zinke K. Sleep divergently affects cognitive and automatic emotional response in children. Neuropsychologia. 2018;117:84-91. https://doi.org/10.1016/j.neuropsychologia.2018. 05.015 .

24. Cox R, van Bronkhorst MLV, Bayda M, Gomillion H, Cho E, Parr ME, et al. Sleep selectively stabilizes contextual aspects of negative memories. Sci Rep. 2018;8(1):17861. https://doi.org/10.1038/ s41598-018-35999-9.

25. Harrington MO, Nedberge KM, Durrant SJ. The effect of sleep deprivation on emotional memory consolidation in participants reporting depressive symptoms. Neurobiol Learn Mem. 2018;152: 10-9. https://doi.org/10.1016/j.nlm.2018.04.013.

26. Jones BJ, Schultz KS, Adams S, Baran B, Spencer RMC. Emotional bias of sleep-dependent processing shifts from negative to positive with aging. Neurobiol Aging. 2016;45:178-89. https:// doi.org/10.1016/j.neurobiolaging.2016.05.019.

27. Kuriyama K, Soshi T, Kim Y. Sleep deprivation facilitates extinction of implicit fear generalization and physiological response to fear. Biol Psychiatry. 2010;68(11):991-8. https://doi.org/10.1016/ j.biopsych.2010.08.015.

28. Prehn-Kristensen A, Molzow I, Förster A, Siebenhühner N, Gesch $\mathrm{M}$, Wiesner CD, et al. Memory consolidation of socially relevant stimuli during sleep in healthy children and children with attentiondeficit/hyperactivity disorder and oppositional defiant disorder: what you can see in their eyes. Biol Psychol. 2017;123:196-204. https://doi.org/10.1016/j.biopsycho.2016.12.017.

29. Wiesner CD, Pulst J, Krause F, Elsner M, Baving L, Pedersen A, et al. The effect of selective REM-sleep deprivation on the consolidation and affective evaluation of emotional memories. Neurobiol Learn Mem. 2015;122:131-41. https://doi.org/10.1016/j.nlm.2015. 02.008 .

30. Cellini N, Mercurio M, Sarlo M. The fate of emotional memories over a week: does sleep play any role? Front Psychol. 2019;10(481). https://doi.org/10.3389/fpsyg.2019.00481.

31. Gilson M, Deliens G, Leproult R, Bodart A, Nonclercq A, Ercek R, et al. REM-enriched naps are associated with memory consolidation for sad stories and enhance mood-related reactivity. Brain sciences. 2015;6(1):1. https://doi.org/10.3390/ brainsci6010001.

32. Greenberg R, Pillard R, Pearlman C. The effect of dream (stage REM) deprivation on adaptation to stress. Psychosom Med. 1972;34(3):257-62. https://doi.org/10.1097/00006842197205000-00007.

33. Groch S, Wilhelm I, Diekelmann S, Sayk F, Gais S, Born J. Contribution of norepinephrine to emotional memory consolidation during sleep. Psychoneuroendocrinology. 2011;36(9):1342-50. https://doi.org/10.1016/j.psyneuen.2011.03.006.

34. Groch S, Wilhelm I, Diekelmann S, Born J. The role of REM sleep in the processing of emotional memories: evidence from behavior and event-related potentials. Neurobiol Learn Mem. 2013;99:1-9. https://doi.org/10.1016/j.nlm.2012.10.006.

35. Johnson JM, Durrant SJ. The effect of cathodal transcranial direct current stimulation during rapid eye-movement sleep on neutral and emotional memory. R Soc Open Sci. 2018;5(7):172353. https://doi. org/10.1098/rsos.172353.

36. Lara-Carrasco J, Nielsen TA, Solomonova E, Levrier K, Popova ANI. Overnight emotional adaptation to negative stimuli is altered by REM sleep deprivation and is correlated with intervening dream emotions. J Sleep Res. 2009;18(2):178-87. https://doi.org/10.1111/ j.1365-2869.2008.00709.x.

37. Lau EYY, Lau KNT, Chan CS, C-h T, Lam YC, Tse DM-S, et al. Effects of REM sleep during a daytime nap on emotional perception in individuals with and without depression. J Affect Disord. 2020;260:687-94. https://doi.org/10.1016/j.jad.2019.09.058.

38. Rosales-Lagarde A, Armony JL, Yd R-P, Trejo-Martínez D, Conde R, Corsi-Cabrera M. Enhanced emotional reactivity after selective REM sleep deprivation in humans: an fMRI study. Front Behav Neurosci. 2012;6:1-13. https://doi.org/10.3389/fnbeh.2012.00025.

39. Sopp MR, Michael T, Weeß H-G, Mecklinger A. Remembering specific features of emotional events across time: the role of REM sleep and prefrontal theta oscillations. Cognitive, Affective, \& Behavioral Neuroscience. 2017;17(6):1186-209. https://doi.org/ 10.3758/s13415-017-0542-8.

40. Werner GG, Schabus M, Blechert J, Wilhelm FH. Differential effects of REM sleep on emotional processing: initial evidence for increased Short-term emotional responses and reduced long-term intrusive memories. Behav Sleep Med. 2020;19:1-16. https://doi. org/10.1080/15402002.2020.1713134.

41. Cunningham TJ, Crowell CR, Alger SE, Kensinger EA, Villano MA, Mattingly SM, et al. Psychophysiological arousal at encoding leads to reduced reactivity but enhanced emotional memory following sleep. Neurobiol Learn Mem. 2014;114:155-64. https://doi.org/ 10.1016/j.nlm.2014.06.002.

42. Lipinska G, Thomas KGF. The interaction of REM fragmentation and night-time arousal modulates sleep-dependent emotional memory consolidation. Front Psychol. 2019;10(1766). https://doi.org/ 10.3389/fpsyg.2019.01766.

43. Kuriyama K, Honma M, Yoshiike T, Kim Y. Memory suppression trades prolonged fear and sleep-dependent fear plasticity for the avoidance of current fear. Sci Rep. 2013;3. https://doi.org/10. 1038/srep02227.

44. Hajcak G, MacNamara A, Olvet DM. Event-related potentials, emotion, and emotion regulation: an integrative review. Dev Neuropsychol. 2010;35(2):129-55. https://doi.org/10.1080/ 87565640903526504.

45. Lewis PA, Cairney S, Manning L, Critchley HD. The impact of overnight consolidation upon memory for emotional and neutral encoding contexts. Neuropsychologia. 2011;49(9):2619-29. https://doi.org/10.1016/j.neuropsychologia.2011.05.009.

46. Payne J, Chambers A, Kensinger E. Sleep promotes lasting changes in selective memory for emotional scenes. Front Integrative Neurosci. 2012;6(108). https://doi.org/10.3389/fnint.2012.00108. 
47. Sterpenich V, Albouy G, Boly M, Vandewalle G, Darsaud A, Balteau E, et al. Sleep-related hippocampo-cortical interplay during emotional memory recollection. PLoS Biol. 2007;5(11):e282. https://doi.org/10.1371/journal.pbio.0050282.

48. Sterpenich V, Albouy G, Darsaud A, Schmidt C, Vandewalle G, Vu TTD, et al. Sleep promotes the neural reorganization of remote emotional memory. J Neurosci. 2009;29(16):5143-52. https://doi. org/10.1523/JNEUROSCI.0561-09.2009.

49. van Marle HJF, Hermans EJ, Qin S, Overeem S, Fernández G. The effect of exogenous cortisol during sleep on the behavioral and neural correlates of emotional memory consolidation in humans. Psychoneuroendocrinology. 2013;38(9):1639-49. https://doi.org/ 10.1016/j.psyneuen.2013.01.009.

50. Wassing R, Lakbila-Kamal O, Ramautar JR, Stoffers D, Schalkwijk F, Van Someren EJW. Restless REM sleep impedes overnight amygdala adaptation. Curr Biol. 2019;29(14):2351-8.e4. https:// doi.org/10.1016/j.cub.2019.06.034.

51. Button KS, Ioannidis JPA, Mokrysz C, Nosek BA, Flint J, Robinson ESJ, et al. Power failure: why small sample size undermines the reliability of neuroscience. Nat Rev Neurosci. 2013;14(5):365-76. https://doi.org/10.1038/nrn3475.

52. Creamer M, O'Donnell ML, Pattison P. The relationship between acute stress disorder and posttraumatic stress disorder in severely injured trauma survivors. Behav Res Ther. 2004;42(3):315-28. https://doi.org/10.1016/S0005-7967(03)00141-4.

53. Weiss D, Marmar C. The Impact of Event Scale-Revised. W. In: Wilson J, Keane T, editors. (red.) Assessing psychological trauma and PTSD: a handbook for practitioners. New York: Guildford Press; 1997.

54. Porcheret K, Holmes EA, Goodwin GM, Foster RG, Wulff K. Psychological effect of an analogue traumatic event reduced by sleep deprivation. Sleep. 2015;38:1017-25. https://doi.org/10. 5665/sleep.4802.

55. Kleim B, Wysokowsky J, Schmid N, Seifritz E, Rasch B. Effects of sleep after experimental trauma on intrusive emotional memories. Sleep. 2016;39(12):2125-32. https://doi.org/10.5665/sleep.6310.

56. Zeng S, Lau EYY, Li SX, Hu X. Sleep differentially impacts involuntary intrusions and voluntary recognitions of lab-analogue traumatic memories. J Sleep Res:e13208. https://doi.org/10.1111/jsr. 13208.

57.• Woud ML, Cwik JC, Blackwell SE, Kleim B, Holmes EA, Adolph $\mathrm{D}$, et al. Does napping enhance the effects of cognitive Bias modification-appraisal training? An experimental study. PLOS ONE. 2018;13(2):e0192837. https://doi.org/10.1371/journal.pone. 0192837 Found that a nap made memories of a traumatic film less intrusive.

58. Sopp MR, Brueckner AH, Schäfer SK, Lass-Hennemann J, Michael T. Differential effects of sleep on explicit and implicit memory for potential trauma reminders: findings from an analogue study. Eur J Psychotraumatol. 2019;10(1):1644128. https://doi.org/ 10.1080/20008198.2019.1644128.

59. Sopp MR, Friesen E, Schäfer SK, Brueckner AH, Wirth BE, Weber $\mathrm{J}$, et al. Wakefulness impairs selective consolidation of relevant trauma-associated memories resulting in more frequent intrusions. Behav Res Ther. 2021;136:103776. https://doi.org/10.1016/j.brat. 2020.103776.

60. Porcheret K, van Heugten-van der Kloet D, Goodwin GM, Foster RG, Wulff K, Holmes EA. Investigation of the impact of total sleep deprivation at home on the number of intrusive memories to an analogue trauma. Translational Psychiatry. 2019;9(1):104. https:// doi.org/10.1038/s41398-019-0403-z.

61. Luik AI, Iyadurai L, Gebhardt I, Holmes EA. Sleep disturbance and intrusive memories after presenting to the emergency department following a traumatic motor vehicle accident: an exploratory analysis. Eur J Psychotraumatol. 2019;10(1):1556550. https://doi.org/ 10.1080/20008198.2018.1556550 Examined the association between sleep and intrusions in participants having experienced an actual traumatic event.

62.• Porcheret K, Iyadurai L, Bonsall MB, Goodwin GM, Beer SA, Darwent M, et al. Sleep and intrusive memories immediately after a traumatic event in emergency department patients. Sleep. 2020;43(8). https://doi.org/10.1093/sleep/zsaa033 Examined the association between sleep and intrusions in participants in the emergency department in the immediate aftermath of an actual traumatic experience.

63.• Sopp MR, Brueckner AH, Schäfer SK, Lass-Hennemann J, Michael T. REM theta activity predicts re-experiencing symptoms after exposure to a traumatic film. Sleep Med. 2019;54:142-52. https://doi.org/10.1016/j.sleep.2018.10.030 Found that theta activity during REM sleep made memories of a traumatic film less intrusive.

64. Ney LJ, Hsu CMK, Nicholson E, Zuj DV, Clark L, Kleim B, et al. The effect of self-reported REM behavior disorder symptomology on intrusive memories in post-traumatic stress disorder. Behav Sleep Med. 2020:1-14. https://doi.org/10.1080/15402002.2020. 1722127.

65. Cox RC, Olatunji BO. A systematic review of sleep disturbance in anxiety and related disorders. Journal of Anxiety Disorders. 2016;37:104-29. https://doi.org/10.1016/j.janxdis.2015.12.001.

66. Palagini L, Baglioni C, Ciapparelli A, Gemignani A, Riemann D. REM sleep dysregulation in depression: state of the art. Sleep Med Rev. 2013;17(5):377-90. https://doi.org/10.1016/j.smrv.2012.11. 001.

67. Zhang Y, Ren R, Sanford LD, Yang L, Zhou J, Zhang J, et al. Sleep in posttraumatic stress disorder: a systematic review and metaanalysis of polysomnographic findings. Sleep Med Rev. 2019;48: 101210. https://doi.org/10.1016/j.smrv.2019.08.004 The most recent and most extensive meta-analysis on sleep in PTSD.

68. Short NA, Boffa JW, Wissemann K, Schmidt NB. Insomnia symptoms predict the development of post-traumatic stress symptoms following an experimental trauma. J Sleep Res. 2020;29(1): e12909. https://doi.org/10.1111/jsr.12909.

69. Harrington MO, Ashton JE, Sankarasubramanian S, Anderson MC, Cairney SA. Losing Control: Sleep Deprivation Impairs the Suppression of Unwanted Thoughts. Clin Psychol Sci. 2021;9(1): 97-113. https://doi.org/10.1177/2167702620951511.

70. Alger SE, Chen S, Payne JD. Do different salience cues compete for dominance in memory over a daytime nap? Neurobiol Learn Mem. 2019;160:48-57. https://doi.org/10.1016/j.nlm.2018.06.005.

71. Davidson P, Hellerstedt R, Jönsson P, Johansson M. Suppressioninduced forgetting diminishes following a delay of either sleep or wake. J Cogn Psychol. 2020;32(1):4-26. https://doi.org/10.1080/ 20445911.2019.1705311.

72. Cox RC, McIntyre WA, Olatunji BO. Interactive effects of insomnia symptoms and trauma exposure on PTSD: examination of symptom specificity. Psychol Trauma. 2018;10(5):508-14. https://doi.org/10.1037/tra0000336.

73. Acheson DT, Kwan B, Maihofer AX, Risbrough VB, Nievergelt CM, Clark JW, et al. Sleep disturbance at pre-deployment is a significant predictor of post-deployment re-experiencing symptoms. Eur J Psychotraumatol. 2019;10(1):1679964. https://doi.org/ 10.1080/20008198.2019.1679964.

74. Dietch JR, Ruggero CJ, Schuler K, Taylor DJ, Luft BJ, Kotov R. Posttraumatic stress disorder symptoms and sleep in the daily lives of World Trade Center responders. J Occup Health Psychol. 2019;24(6):689-702. https://doi.org/10.1037/ocp0000158.

75. Marcusson-Clavertz D, West M, Kjell ONE, Somer E. A daily diary study on maladaptive daydreaming, mind wandering, and sleep disturbances: examining within-person and between-persons relations. PLoS One. 2019;14(11):e0225529. https://doi.org/10. 1371/journal.pone.0225529. 
76. Azza Y, Wilhelm I, Kleim B. Sleep early after trauma. Eur Psychol. 2020:1-13. https://doi.org/10.1027/1016-9040/a000401.

77. Repantis D, Wermuth K, Tsamitros N, Danker-Hopfe H, Bublitz $\mathrm{JC}$, Kühn S, et al. REM sleep in acutely traumatized individuals and interventions for the secondary prevention of post-traumatic stress disorder. Eur J Psychotraumatol. 2020;11(1):1740492. https://doi. org/10.1080/20008198.2020.1740492.

78. Hertenstein E, Feige B, Gmeiner T, Kienzler C, Spiegelhalder K, Johann A, et al. Insomnia as a predictor of mental disorders: a systematic review and meta-analysis. Sleep Med Rev. 2019;43: 96-105. https://doi.org/10.1016/j.smrv.2018.10.006.

79. $\mathrm{Li} \mathrm{L}, \mathrm{Wu} \mathrm{C}, \mathrm{Gan} \mathrm{Y}, \mathrm{Qu} \mathrm{X}, \mathrm{Lu} \mathrm{Z}$. Insomnia and the risk of depression: a meta-analysis of prospective cohort studies. BMC Psychiatry. 2016;16(1):375. https://doi.org/10.1186/s12888-0161075-3.

80. Gehrman P, Seelig AD, Jacobson IG, Boyko EJ, Hooper TI, Gackstetter GD, et al. Predeployment sleep duration and insomnia symptoms as risk factors for new-onset mental health disorders following military deployment. Sleep. 2013;36(7):1009-18. https://doi.org/10.5665/sleep.2798.

81. Koffel E, Polusny MA, Arbisi PA, Erbes CR. Pre-deployment daytime and nighttime sleep complaints as predictors of postdeployment PTSD and depression in National Guard troops. Journal of anxiety disorders. 2013;27(5):512-9. https://doi.org/10. 1016/j.janxdis.2013.07.003.

82. Wang HE, Campbell-Sills L, Kessler RC, Sun X, Heeringa SG, Nock MK, et al. Pre-deployment insomnia is associated with post-deployment post-traumatic stress disorder and suicidal ideation in US Army soldiers. Sleep. 2018;42(2). https://doi.org/10. 1093/sleep/zsy229.

83. van Liempt S, van Zuiden M, Westenberg H, Super A, Vermetten E. Impact of impaired sleep on the development of PTSD symptoms in combat veterans: a prospective longitudinal cohort study. Depression and anxiety. 2013;30(5):469-74. https://doi.org/10. 1002/da.22054.

84. Bryant RA, Creamer M, O’Donnell M, Silove D, McFarlane AC. Sleep disturbance immediately prior to trauma predicts subsequent psychiatric disorder. Sleep. 2010;33(1):69-74. https://doi.org/10. 1093/sleep/33.1.69.
85. John-Henderson NA, Williams SE, Brindle RC, Ginty AT. Changes in sleep quality and levels of psychological distress during the adaptation to university: the role of childhood adversity. Br J Psychol. 2018;109(4):694-707. https://doi.org/10.1111/bjop.12314.

86. Koskenvuo K, Hublin C, Partinen M, Paunio T, Koskenvuo M. Childhood adversities and quality of sleep in adulthood: a population-based study of 26,000 Finns. Sleep Med. 2010;11(1): 17-22. https://doi.org/10.1016/j.sleep.2009.03.010.

87. Christensen H, Batterham PJ, Gosling JA, Ritterband LM, Griffiths $\mathrm{KM}$, Thorndike FP, et al. Effectiveness of an online insomnia program (SHUTi) for prevention of depressive episodes (the GoodNight Study): a randomised controlled trial. Lancet Psychiatry. 2016;3(4):333-41. https://doi.org/10.1016/S22150366(15)00536-2.

88. Gruber R, Cassoff J. The interplay between sleep and emotion regulation: conceptual framework empirical evidence and future directions. Current Psychiatry Reports. 2014;16(11):500. https:// doi.org/10.1007/s11920-014-0500-x.

89. Minkel JD, Banks S, Htaik O, Moreta MC, Jones CW, McGlinchey EL, et al. Sleep deprivation and stressors: evidence for elevated negative affect in response to mild stressors when sleep deprived. Emotion. 2012;12:1015-20. https://doi.org/10.1037/a0026871.

90. Palmer CA, Alfano CA. Sleep and emotion regulation: an organizing, integrative review. Sleep Med Rev. 2017;31:6-16. https://doi. org/10.1016/j.smrv.2015.12.006 A review paper that emphasizes how research on sleep and emotion must start delineating between the different underlying processes that are believed to be affected by sleep.

91. Tamm S, Nilsonne G, Schwarz J, Golkar A, Kecklund G, Petrovic $\mathrm{P}$, et al. Sleep restriction caused impaired emotional regulation without detectable brain activation changes - a functional magnetic resonance imaging study. R Soc Open Sci. 2019;6(3):181704. https://doi.org/10.1098/rsos.181704.

92. Pilcher JJ, Huffcutt AI. Effects of sleep deprivation on performance: a meta-analysis. Sleep. 1996;19(4):318-26. https://doi.org/10. 1093/sleep/19.4.318.

Publisher's Note Springer Nature remains neutral with regard to jurisdictional claims in published maps and institutional affiliations. 